\title{
HYGROTHERMAL PERFORMANCE OF OLD LIME PLASTERED SPACES IN A HOT AND DRY CLIMATE
}

\author{
VISMAYA PARALKAR. ${ }^{1}$ \& DR. RASHMIN DAMLE. ${ }^{2}$ \\ ${ }_{1,2}^{2}$ CEPT University, Ahmedabad, India \\ ${ }^{1}$ vismaya.pg181207@cept.ac.in, ${ }^{2}$ rashmin.damle@cept.ac.in
}

\begin{abstract}
.
Lime plaster is one of the key sustainable building materials which is also effective as a passive cooling strategy. Since it is being used for ages now, it is the most compatible material for old heritage structures. Thus, majorly used in conservation projects. In this work, the hygrothermal performance of lime plaster is observed through simulations and surveys. Residential surveys are carried out for occupied old naturally ventilated spaces. The inner surface temperature, relative humidity, and moisture content of the walls are measured. Simultaneously, the indoor air temperature, relative humidity, globe temperature, and air velocity are measured. In hygroscopic materials like lime plaster, realistic conditions like mold growth cannot be predicted through simulations. A simulation of thermal and hygrometric behavior of historical buildings is a challenge. An inaccurate simulation may lead to inadequate conclusions, which could lead to inappropriate and dangerous actions for the building's heritage conservation. An attempt is made to use the survey readings and observations to predict the phenomenon of mold growth in a space while conducting simulations. Using a combined approach of simulation and survey, it was possible to predict the mold risk of the space.
\end{abstract}

Keywords: Lime plaster, Hygrothermal simulations, historical buildings, mold growth, surface relative humidity conditions.

\section{Introduction}

Before the 20th century, lime has been the most commonly used binder in building construction. The versatile nature of lime is beneficial in construction as well as finishing on wall surfaces. Snow and Torney (2014) discussed the applicability of lime in buildings as extensive, from concrete to bedding and pointing mortars to harling and paint (limewash). Depending on the nature of the lime binder used to prepare along with the effect of additives in the mixture, the properties of a lime mortar/plaster vary.

While describing the proportions to obtain durable plaster in ancient times, De Luca et al. (2016) mentions that the sand is mixed in three parts to one part of slaked lime. Ravi and Thirumalini (2018) describe the organic additives used, their application technology, the process of making mortar, and the advantages of lime plaster.

Lime mortar and lime plaster are self-healing and thus prevent the formation of inner cracks. Moreover, because of its durability, it has a longer life span. This reflects the fact that the life of a cement concrete is only for around 50 years, while the life of a lime starts after 70 years. Thus, reinforcing that old historical structures that are thousands of years old are still functioning and strong.

The advantageous properties of lime are encouraging progressively more architects to opt for using lime over cement. Lime plaster and mortar is essentially used in conservation projects. It vastly adds up to the qualities of the old building. Homes, Roger, and June (2020) have specified that in old structures an important function is the breathability of ceiling and walls. The moisture must evaporate through the envelope to prevent dampness and condensation. Unfortunately, modern materials like cement-based plasters or gypsum plasters are used nowadays. These materials are non-breathable and inflexible which seal the moisture. This, in the long run, damages the structure. Thus, it is important to use the same original plaster in conservation projects which is lime plaster in most cases.

It should be tested if the presence of mold or such favorable environments affects the performance of lime plaster in that space. For such situations, it is required to know the controllable parameters 
to optimize the performance of the lime plaster. The impact of using lime plaster on the indoor environment in old naturally ventilated spaces should be understood.

\section{Literature Review}

In the literature review the overall history, chemical structure, advantages, disadvantages, hygrothermal studies of lime plaster is understood.

\section{LIME AS A PASSIVE STRATEGY WITH MOISTURE BUFFERING}

Energy Consumption and building performance is highly dependent on the indoor air relative humidity. The influence of hygrothermal properties of building materials on the consumption of cooling load in five climate zones of India as assessed by Damle and Rawal (2018) evaluates this fact. According to Busser et al. (2018), it is also responsible for the indoor air quality and climate of that building. Therefore, it is necessary to maintain this relative humidity level inside. However, the moisture buffering quality of the building materials which absorb and release the moisture modulates the indoor humidity. Using the analytical methods by Liu and Shun (1991), the authors Gaur and Bansal (2002) and Hall, Hoff and Nixon (1984) derived that the humidity present in ambient air and room air can modify up to $2-3{ }^{\circ} \mathrm{C}$ of room temperature with respect to the amount and direction of temperature and moisture gradients. According to Labat and Woloszyn (2015), the vapor transfer and its storage have a significant impact on heat transfer, indoor comfort, and durability of the wall assemblies. So, to avoid envelope damage, repour open wall assembly is a better option over vapor-tight assembly.

Padfield (1998) experimented to understand the effectiveness of porous, water-absorbent walls performing as moisture buffers for occupied rooms at $0.5 \mathrm{ACH}$. Absorbent materials can be used as a buffer for a brief period and can substitute for mechanical ventilation. For over a longer period, the performance of the absorbent buffers is not as effective as ventilation. So, along with buffering proper ventilation must be also maintained for the effective performance of the pace.

Toniolo et al. (2011) recommend lime plaster as useful in 'breathing wall' construction. Along with increasing its strength eventually, it is an easy remediation to cracks and defects. It involves nontoxic chemicals for manufacturing, production can be downscaled as per need, it is recyclable in use, has a porous surface after curing, highly reflective if in natural white color. When used as an internal render, it improves the indoor air quality by absorbing low amounts of Carbon dioxide and regulating the indoor relative humidity for a prolonged period.

\section{DECLINE AND DRAWBACKS OF LIME PLASTER}

According to (Sickels, 1987), Joseph Aspdin in 1824 patented the term Portland cement. I.C. Johnson after 19 years, prepared a type of Portland cement, very similar to today's cement type. With these progresses, the use of lime mortar gradually declined. Thus, there was a shift from lime technology to cement technology.

The high risk of mold growth in lime plastered spaces is probably the other reason. In the paper by Bastien and Winther-Gaasvig (2018), best and worst-case scenarios are assessed in terms of the possible influence of rain exposure on hygrothermal performance. It is concluded that the rain exposure impact on hygrothermal performance is minor. But the impact is significant on mold index for a lime plaster assembly as compared to mineral-cement based plaster. Karaglozls et al. (1995) observed that materials like lime plaster have higher capillary action and its moisture content is vastly dependent on their exposure to driving rain. Although, $2 \%-9 \%$ of heat losses due to latent heat and rise in thermal conductivity are found in building materials having higher moisture content. Elert et al. (2002) stated that the presence of moisture in or on the surface of walls invites a favorable atmosphere for mold growth. The mold damage and moisture ingress frequently occur even after the renovation of a damaged building. Fungal growth in buildings is influenced by the nutrient, relative humidity, temperature, and so on. The fungal growth inside a 
space is highly influenced by the relative humidity (RH) inside the dwelling. These RH levels inside are further an effect of the moisture buffering capacity of the wall assemblies, ceiling coverings, furniture, and textiles used inside the building. Lucas et al. (2002) and Mendes et al. (2003) found that the presence of moisture is a cause of deteriorations inside buildings while affecting the latent and sensible conduction loads.

Lstiburek. (2009) states that if the rate at which moisture entering into an assembly surpasses its rate of moisture removal, the moisture starts accumulating. This furthermore results in moisture problems if the moisture accumulated is exceeding the assembly's ability to store it. Moreover, the problem of even small water leak has a significant impact if the hygric buffer capacity of the material is low while for higher hygric buffer capacity materials it's not.

Older buildings without the vapor barriers are highly prone to structural damage due to moisture diffusion inside the wall and condensation on the outside. Variations in the location of humidity sources and room ventilation rates give rise to pockets of high relative humidity. Therefore, the average relative humidity throughout the building should be maintained between 40 to $60 \%$.

\section{SOLUTION TO MOLD GROWTH AND REINTRODUCTION.}

While studying the use of lime Plaster on Malaysian heritage building, Sabri and Suleiman (2014) found that the use of incompatible materials like cement plaster or chemical paint on the wall causes deterioration. It traps the moisture inside and soon the walls crumble and fall off. A similar kind of observation is mentioned in Ingham and Ingham (2016).

A transition is seen in the use of lime materials for repairing historic buildings. Awareness about the use of well-suited materials in the restoration of old buildings is growing. Conservationist has recognized the unfavorable properties of Portland cement. This marks the rebirth of lime application and technology. Whereas, structures that are constructed 30 years earlier are still in service without much maintenance.

Čáchová et al. (2016) experimented with lime cement plasters and found that on increasing the amount of pozzolana in a mixture, the values of the water vapor diffusion coefficient went down. Thus, Govaerts et al. (2018) imply that renders for historical buildings should have strong buffering towards water absorption to achieve thermal comfort and reduce the risk of damage.

Doctor-pingel et al. (2019) has studied two lime plaster buildings in Auroville for its postoccupancy thermal performance. It is proved that using lime plaster as building material optimizes the thermal performance of the buildings in warm and humid climates. There was a difference of $10.7 \%$ noticed between the façade temperatures and cooler interior surfaces than the exterior by $16.8 \%$ for the case study of Language Lab.

\section{Scope Of Current Work.}

It is clear from the literature that lime plaster/mortar has several advantages like lower RH levels and lower indoor temperature. However, the main problem is mold growth due to its moisture absorbing capacity and use of additives. Therefore, in this study, an attempt has been made to evaluate the state of old lime plastered buildings in Ahmedabad and correlate the results in terms of the building characteristics like coatings on the wall, the moisture content of the walls, and the indoor RH levels. Simulations are also carried out to understand the hygrothermal performance of lime plaster and predict the chances of mold growth in the space.

\section{Methodology}

The research methodology adopted in this work is divided into two sections and each section is discussed in this chapter: 
- Simulating the studied spaces with an Effective Moisture Penetration Depth (EMPD) Model using Energy Plus (2019).

- Survey of old lime plastered spaces.

The above two methods can help us derive the hygrothermal impact of lime plaster in an actual case scenario of naturally ventilated buildings. The capability of the EMPD model to predict hygrothermal performance is verified by carrying out annual simulations and contrasting the simulation results with those observed onsite. Survey's also helped to understand the factors which lead to mold growth on lime plastered surfaces in old structures.

\section{SIMULATING THE STUDIED SPACES WITH THE EMPD MODEL.}

To carry out a hygrothermal simulation with the EMPD model, hygrothermal properties of lime plaster and other base materials like (brick and concrete) are needed. Properties of the base material required for the EMPD model are available in EnergyPlus v9.1.o (2010) data. However, there is little information about the hygric properties for lime plaster which could be used, because of its non-standardized compositions. This is one of the reasons for selecting the EMPD model which requires lesser hygric properties as compared to a detailed hygrothermal model in Energy Plus.

Lime mortar mixes are always site-specific making it a challenge to derive a universal curve for it. Therefore, moisture content values required in the input are referred from Kielsgaard (1986) catalog of building materials. To derive the sorption coefficients through these moisture content values, a close-fitting curve shown in

Figure is plotted. The values of this curve are then fed in the EMPD model and simulated.

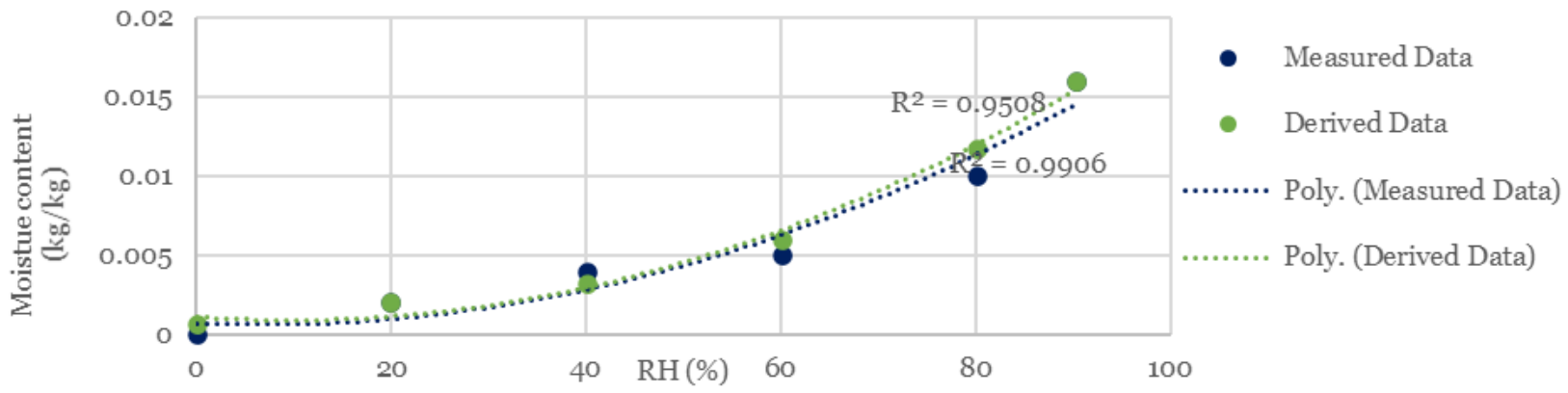

Figure 1 Best fitted sorption curve for lime plaster.

A BESTEST model referred from Judkoff and Neymark (1998) is used and validated by several other authors Woods, Winkler, and Christensen (2013), Zemanová et al. (2017), Zhang et al. (2017), Tran Le et al. (2010) for hygrothermal simulation. It is a single-zone shoe-box model with a continuous source of 500 grams per hour of moisture and air exchange per hour is given as 0.5 per hour.

To support the working of hygrothermal simulation in EMPD, first the model is run using thermal only and EMPD algorithm. Later, a sample study space from the survey is modeled and then simulated. The change in MRT and relative humidity through simulation can be derived. This further can help to understand the trend of the hygrothermal behavior of lime plaster in that space throughout the year.

\section{SURVEY OF RESIDENTIAL SPACES}

The heritage city of Ahmedabad majorly comprises of thousands of pols, dense cluster of residences belonging to the same caste, religion, and occupation. The houses of such a 
neighborhood for more than 300 years are popularly known as Pol houses. The typical pol house has minimal frontage to a narrow lane, long shared walls, some have a central courtyard, multistory structure. The construction of the house is of timber, brick, and lime plaster. The Pols are well known for their passive strategies of cooling. Due to the narrow lanes and dense clusters, the lanes and houses are often shaded and not so windy. Daily activities of the occupants keep the microclimate humid. The house protects the inside spaces from heat gain by providing cool surfaces, more humid air, and shade.

The point in time surveys are carried out in the afternoon when the temperatures are relatively high outside on every alternate day from the December end. A layout of the space is created considering the wall thickness, opening area, and adjacent spaces. The use and activities of the space are also noted. Table gives the details of the parameters and the location measured on-site by the respective instruments.

Table 1 List of instruments for their measured parameters

\begin{tabular}{|l|l|l|}
\hline Instrument used & Parameter measured & Measurement location \\
\hline $\begin{array}{l}\text { Heat Stress WBGT Meter } \\
\text { Extech HT30) }\end{array}$ & $\begin{array}{l}\text { Outside air temperature, } \\
\text { Relative Humidity, Black Globe } \\
\text { Temperature }\end{array}$ & $\begin{array}{l}\text { Outside the survey space at a height of 1100 mm from the } \\
\text { ground }\end{array}$ \\
\hline $\begin{array}{l}\text { Heat Stress WBGT Meter } \\
\text { (Extech HT30) }\end{array}$ & $\begin{array}{l}\text { Inside air temperature, relative } \\
\text { humidity, Black Globe } \\
\text { Temperature }\end{array}$ & $\begin{array}{l}\text { At the center of survey space at a height of 1100 mm from the } \\
\text { FFL. }\end{array}$ \\
\hline $\begin{array}{l}\text { Vane Anemometer } \\
\text { (PEAKMETER MS6252A). }\end{array}$ & Air velocity & $\begin{array}{l}\text { 1. Near the globe thermometer perpendicular to three planer } \\
\text { axes. } \\
\text { 2. Perpendicular to the vertical plane of the openings inside a } \\
\text { space. }\end{array}$ \\
\hline $\begin{array}{l}\text { Thermal Gun (FLIR } \\
\text { TG165) }\end{array}$ & $\begin{array}{l}\text { Inside and outside exposed surfaces of all the walls } \\
\text { surrounding the space. }\end{array}$ \\
\hline $\begin{array}{l}\text { Testo 606-2 Moisture } \\
\text { Meter (38767439/711) }\end{array}$ & $\begin{array}{l}\text { Moisture Content and surface } \\
\text { relative humidity. }\end{array}$ & $\begin{array}{l}\text { Moisture content inside lime plaster and surface relative } \\
\text { humidity near it. }\end{array}$ \\
\hline
\end{tabular}

\section{Results}

The results are described in detail for simulations and surveys in this chapter.

\section{SIMULATION RESULTS OF BESTEST MODEL}

To understand the moisture buffering of a hygrothermal model, thermal only and EMPD simulations are conducted. The simulations are done in a naturally ventilated mode using the BESTEST model. Moisture buffering can be effectively observed in Figure 2 of the relative humidity inside the space.

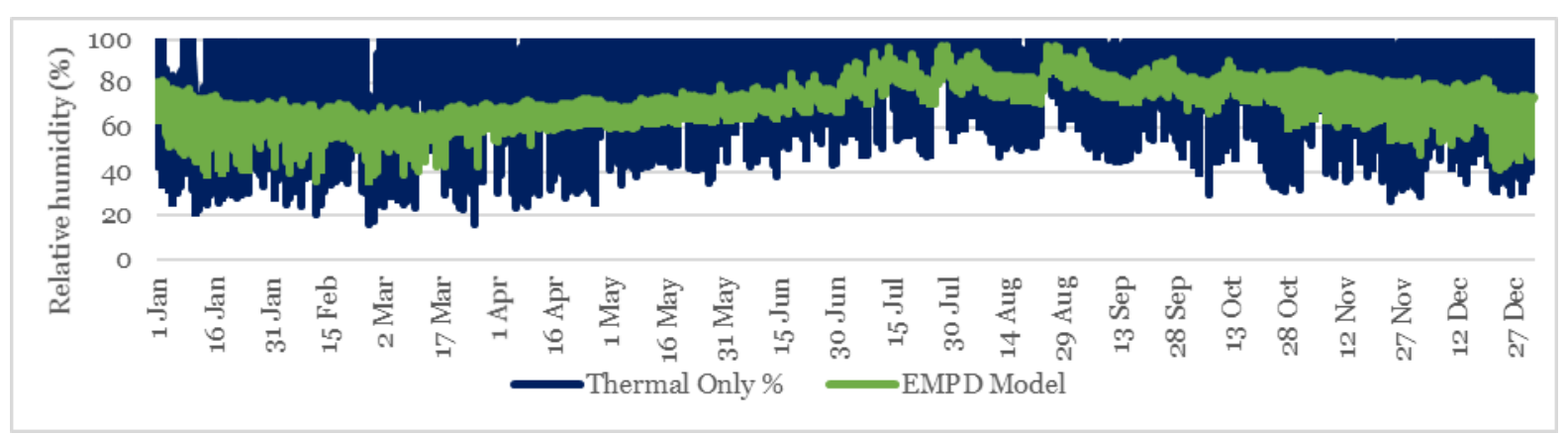

Figure 2 Relative Humidity BESTEST Model of Thermal Only and EMPD.

It can be seen that the RH levels in the case of the Thermal only model (CT) model reach 100\% at times. While for the hygrothermal model of lime plaster, the RH levels are maintained between 39\% to 95\%. This shows that the EMPD model (EnergyPlus v9.1.0, 2010) of lime plaster is successfully showing the moisture buffering inside the space. 
After verifying this behavior of the EMPD model for its realistic physical predictions, further simulations in the same EMPD are carried out for the hygrothermal performance of a sample space from the survey. Its performance in terms of MRT and RH inside is observed throughout the year.

\section{SIMULATION RESULTS OF SURVEY SAMPLE SPACE}

An onsite space (PT_B) where mold growth is observed during the survey is selected for modeling. Physical parameters similar to the actual case are created except for the lime composition as it is unknown for the actual case. In this case, there is no external source of moisture other than occupancy. Figure 3 shows the layout of the space selected for modeling.
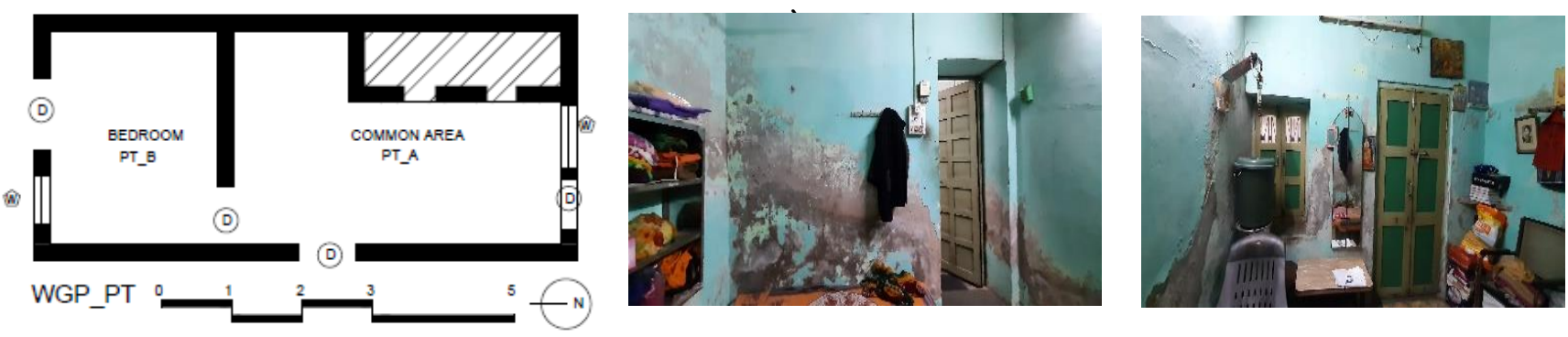

Figure 3 Typical layout of the simulated space PT_B and onsite images.

Figure 4 shows the difference in temperature observed from outside (To) to inside ambient (Ta) throughout the year for model PT_B. The diurnal variation is decreasing from outside to inside. The outside DBT has varying amplitude with a maximum diurnal variation of $20^{\circ} \mathrm{C}$ in winters to a minimum variation of $7^{\circ} \mathrm{C}$ in monsoon. Whereas there is a variation of around $5^{\circ} \mathrm{C}$ for indoor air temperature. Similarly, the bandwidth (difference of maximum and minimum) of the MRT inside the space is around $2^{\circ} \mathrm{C}$. Hardly any fluctuations are observed in this band and the temperature is maintained between 20 to $30^{\circ} \mathrm{C}$ for the given geometry.

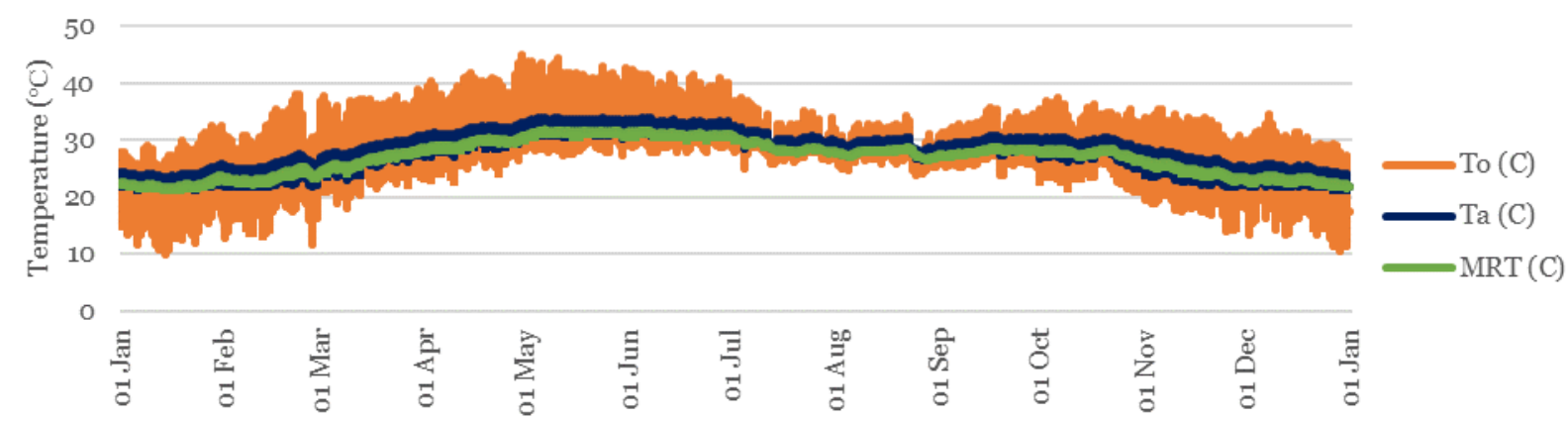

Figure 4 Simulations results showing a range of outdoor, indoor, and MRT in PT_B.

The outside relative humidity (RHo) is compared with the inside RH levels (RHi) and the surface $\mathrm{RH}$ (RHs) level in Figure 5. There is a difference of $\mathbf{1 1 . 5 \%}$ from the maximum of outside to inside. Whereas $11 \%$ of difference is observed between the minimum levels of outside RH and Inside RH. Also, the difference between the first quartile and third quartile is $33 \%$ for outside $\mathrm{RH}$ and $24 \%$ for the Inside RH. 


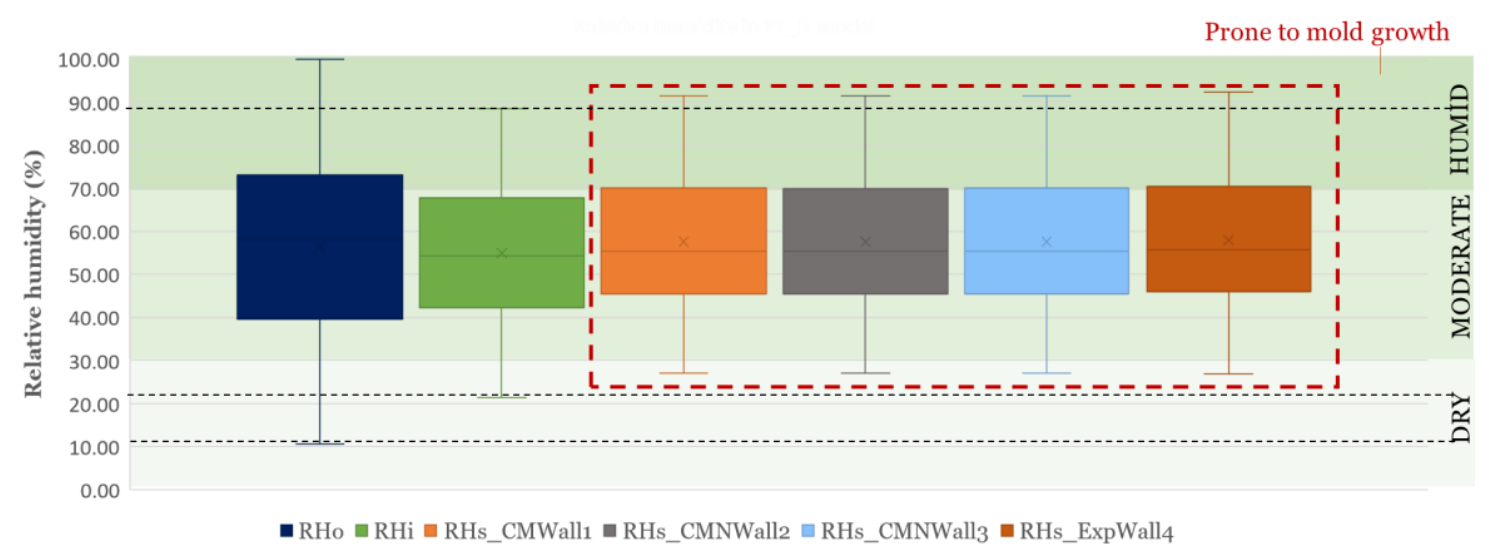

Figure 5 Relative Humidity levels of space and on the surface of the walls in PT_B.

It can be predominantly seen that the surface RH (RHs) levels are higher than the inside RH (RHi) levels. The maximum RHs values are high by $3 \%$ and a minimum of RHs are high by $7 \%$ than the maximum and minimum of RHi. ASHRAE suggests that to prevent mold growth it is necessary to keep the spaces below 60\% RH (Taylor et al., 1999). However, 25\% of the surface RH values are more than $70 \%$ leading to mold risk.

Figure 6 further indicates the varying RH levels throughout a year. During the monsoon months from July, the inside $\mathrm{RH}$ is always above 60\%. While the surface $\mathrm{RH}$ of common wall (RHs_CMWall1) and exposed wall (RHs_ExpWall4) of the walls is always above 68\%. These are the months when the wall surfaces are highly prone to mold growth.

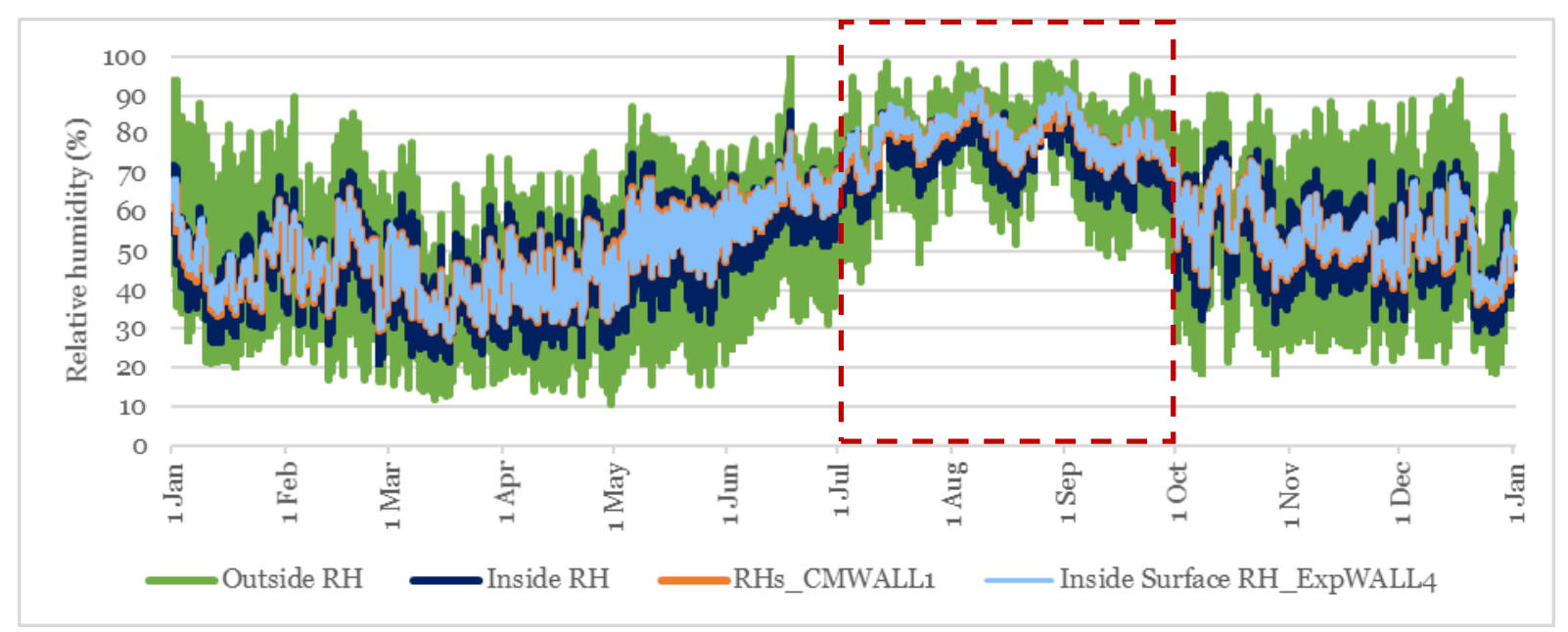

Figure 6 Varying RH levels with time throughout the year in PT_B.

The number of hours when the RH levels are favorable for mold growth can be observed in Figure 7 Out of 8760 hours, 32 to 54 hours are above $90 \%$ near the walls. Whereas, $60 \%$ of the hours are between 60 to $90 \%$. Rest $40 \%$ is below $60 \% \mathrm{RH}$ levels. Thus, a cumulative of more than $60 \%$ of the time the walls are at a risk of mold growth. Unlike the simulation results where an equal percentage of surface RH (RHs) on the walls is observed, the percentage of mold growth observed on-site over each wall is different indicating varying surface RH levels (RHs). This gap can be because of the several ignored factors like placement of furniture and belongings, material of the possessions inside the space, etc. 


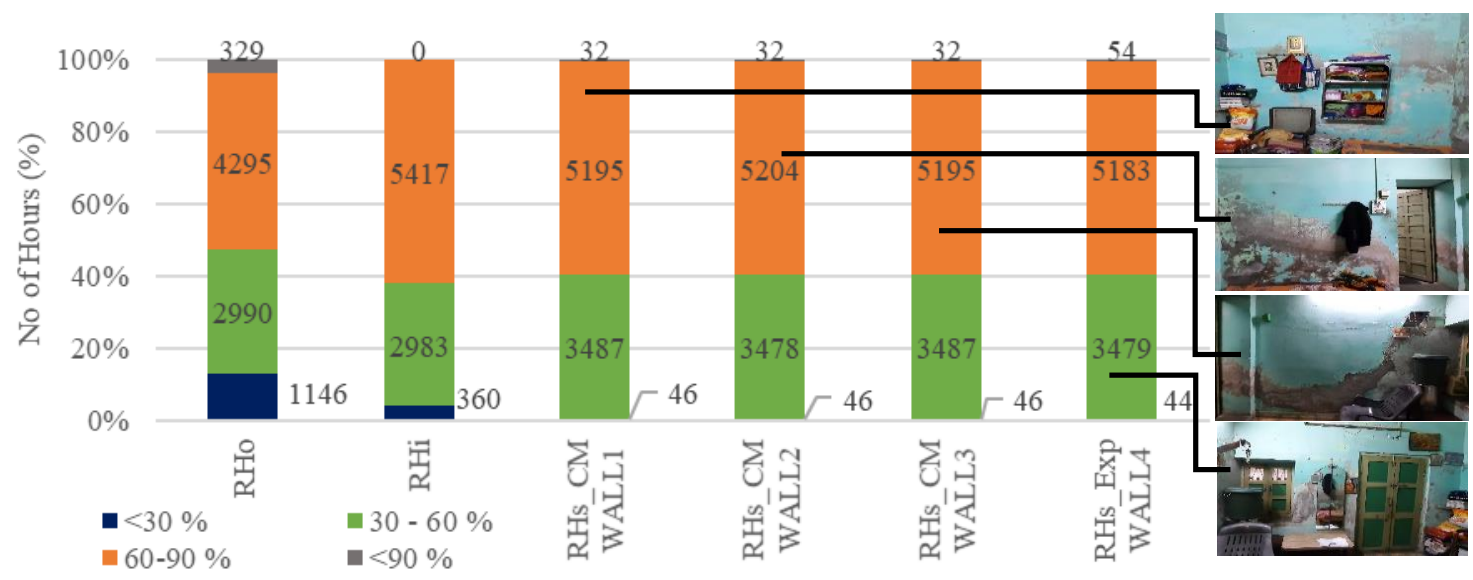

Figure 7 PT_B RH levels observed throughout the year with respect to the number hours.

\section{Survey Results:}

The observations in studied pol houses are categorized according to the coatings used over lime plaster. According to Figure 8, for the studied time-span from December to March the outside RH levels are between $10 \%$ to $55 \%$. However, the minimum value is higher inside by $2.1 \%$ in limewash houses and by $1 \%$ in Non-porous paint. The median of limewash readings is higher by $3 \%$ and in non-porous it is $1 \%$ from the outside. For outside $\mathrm{RH}$ below $15 \%$, the inside $\mathrm{RH}$ is high. The reason can be moisture buffering of the material, occupancy, and inside moisture generation rate.
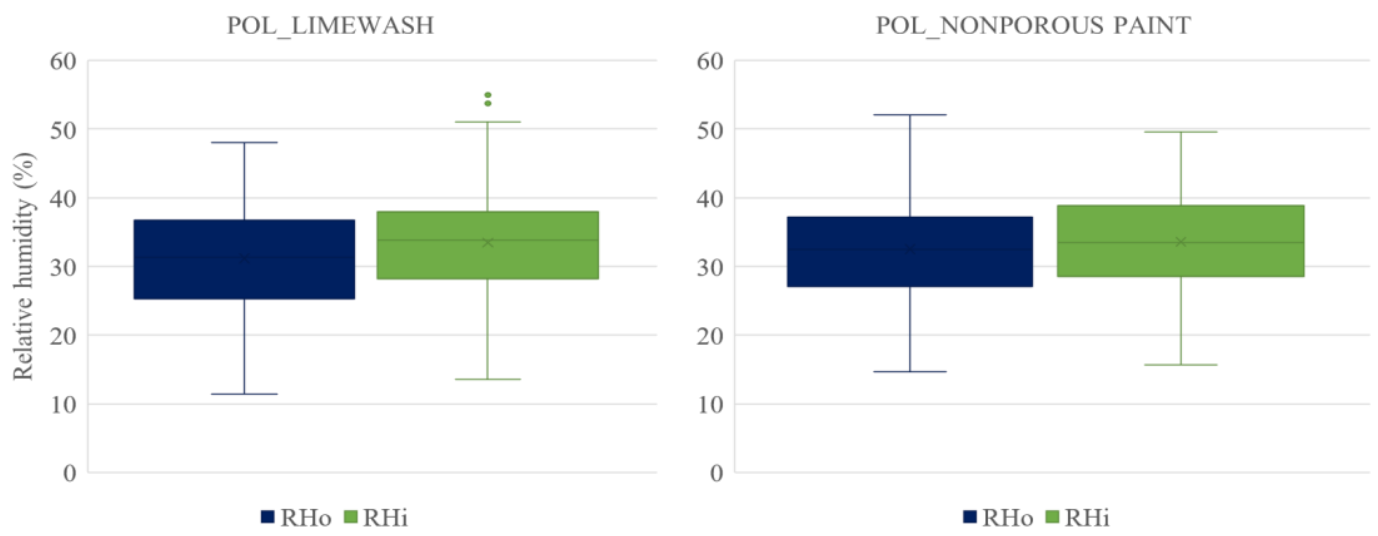

Figure 8 RH levels of studied POL houses.

The inside and outside temperatures in both cases are plotted in Figure 9. In spaces having limewash, the air temperature is lower by $1^{\circ} \mathrm{C}$. For non-porous finish, the inside ambient temperature is lower by $1.4^{\circ} \mathrm{C}$ from the outside high. The outliers observed are the readings when the space is exposed to solar radiation. Otherwise, the rest of the spaces are always under shade.

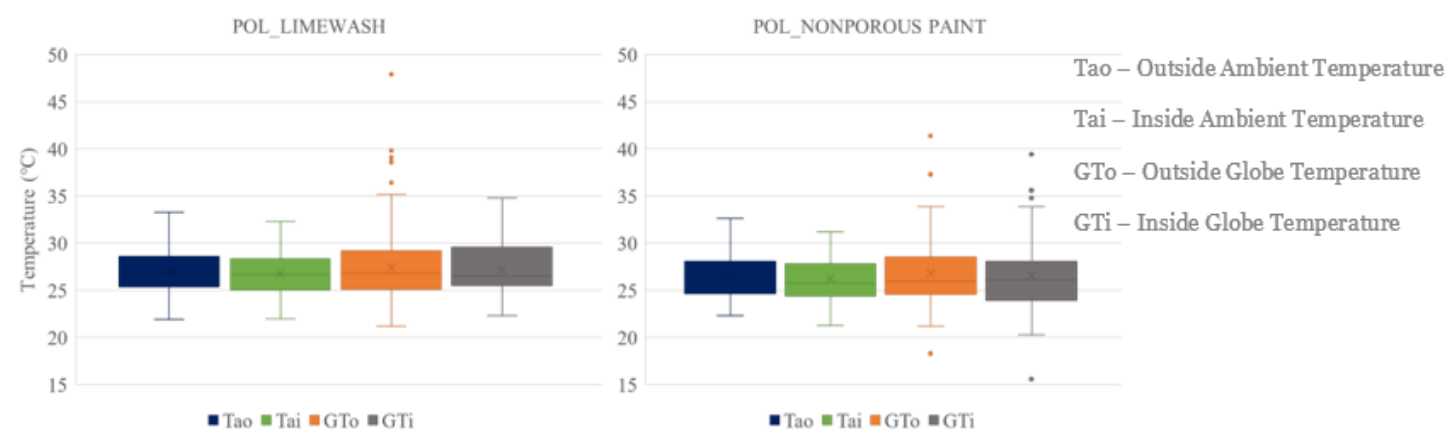

Figure 9 Temperature levels of studied POL houses. 
To further examine the simulation observations for sample space PT_B, the onsite readings are analyzed. In Figure 10, the outside relative humidity is compared with the inside space RH levels and the surface RH levels from January to March.

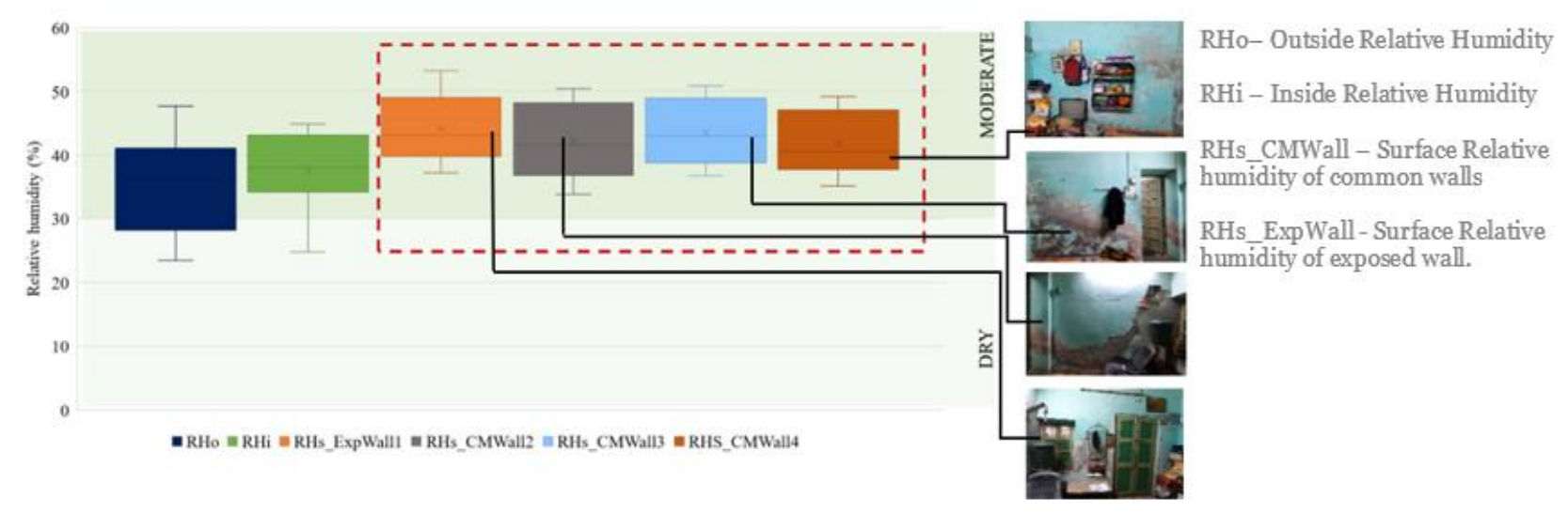

Figure 10 Onsite RH levels inside PT_B

Similar to the simulation results (refer Figure 5), surface RH (RHs) levels are higher than the inside RH (RHi) levels. The maximum of RHi is less by $2.85 \%$ from the maximum of RHo of that space. Whereas only a $1.3 \%$ of difference is observed between the minimum levels of outside (RHo) and inside (RHi) readings. Thus, moisture buffering is observed. However, $50 \%$ of the readings are higher inside than the outside indicating it to be humid inside. So, if the above pattern is followed throughout the year, whenever the space RH goes above $60 \%$, the surface of the wall will have around 65 to $70 \% \mathrm{RH}$. In the monsoon period when the outside RH levels are in the range of 8095\%, the RH inside the space can be around $91 \%$. Similarly, RH near the walls can be predicted to reach 95 to $97 \%$. At this $\mathrm{RH}$ level, if the moisture is not removed from the surface, it gets prone to mold growth.

\section{MRT OBSERVATIONS}

The percentage of time when MRT inside a space is higher than the outside in March is plotted in the graph below Figure 11. This graph indicates that 30\% of the time it was hotter inside for nonporous paint spaces. For limewash coated spaces the percentage was $18.52 \%$.

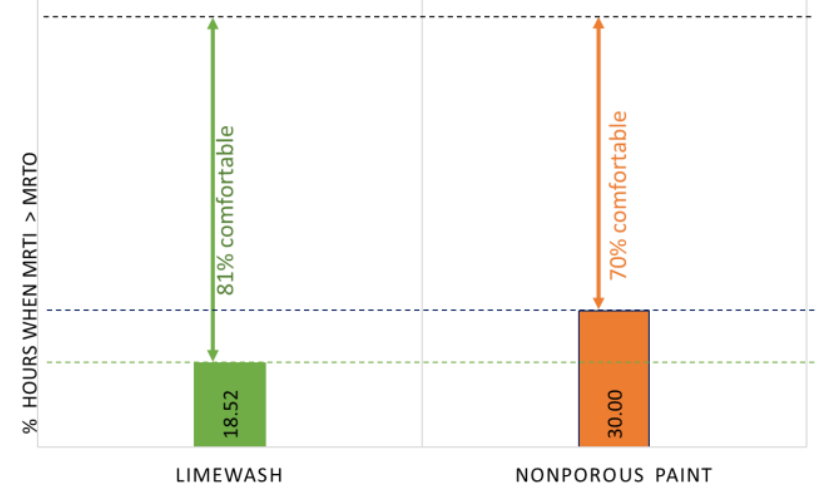

Figure 11 Percentage of readings Inside MRT > Outside MRT in March

\section{MOLD RISK OBSERVATIONS}

On conducting the survey, it is observed that the hygrothermal behavior of a space varies as per its characteristics. The spaces are identified and observed separately based on the topmost finish of the wall surface layer, air velocity inside the space, occupancy, storage, the sunlight received and the type of activity happening in that space. Moreover, these were the factors that have a high influence on the high humidity conditions inside any space. The observations analyzed that 
majorly the spaces which had mold are devoid of sunlight, lacked ventilation, had a lot of storage, and had water storage nearby.

Further analysis of the moisture content recorded of the walls is shown in figure 12. The walls of the spaces where mold growth is observed are marked in orange. Majorly all the walls of the studied spaces from December to March had low moisture content below 2\%. Walls below 2\% moisture content are drywalls and do not poses any damage due to mold growth. However, mold growth is still observed on these walls which indicate that during the monsoon season in the past the mold growth was initiated from within. This happens when the surface relative humidity of the walls goes above $60 \%$. Other factors like damaged construction, presence of water pipelines, low ventilation, etc. are also the reasons.

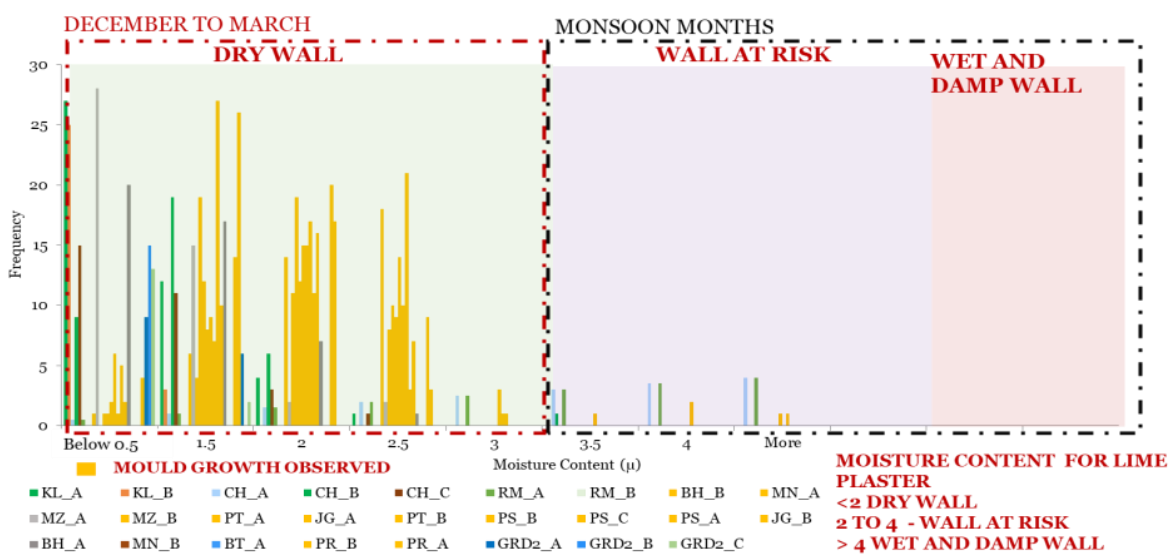

Figure 12 Moisture content of all walls studied from December to March.

\section{Conclusion}

This work focused on the hygrothermal performance of lime plastered traditional buildings in hot and dry climate. Simulations carried out with the EMPD model can predict the moisture buffering phenomenon on wall surfaces. Thus, it can also be used to predict the mold growth risk of different surfaces. However, more numerical analysis with hygrothermal properties of typical lime plaster used in India needs to be carried out for realistic predictions.

The point in time survey of old naturally ventilated spaces concluded that the finishing coat applied over lime plaster alters its properties and characteristics. If lime plaster is coated with nonporous coatings, that affects its hygrothermal performance. It is not able to maintain effective MRT difference from outside to inside. However, more measurements are necessary to derive definitive conclusions.

The surface RH near the walls is higher than the ambient by 5 to $6 \%$ for the surveyed spaces of hot and dry climate. Identifying the high humidity period and hours of the high RH exposure through simulations can further benefit in using preventive measures to reduce the moisture damage of those spaces. This at the design stage will prove to be an important tool to formulate the strategies for maintenance.

Lime Plaster as a building material effectively maintains the $\mathrm{RH}$ levels inside naturally ventilated the space. Taken the proper precautions, it is one of the most sustainable building materials that can be used in the building industry today as well. One important aspect to consider is preventing moisture from getting trapped into building fabrics.

The hygrothermal simulations are necessary for predicting the hygrothermal behavior of a material. However, to analyze the historical buildings using only simulations cannot be a good idea. Numerical simulations can just give you a rough idea of what is happening depending upon the input sources. Still, there are a lot of discrepancies with the actual case scenario. As (Akkurt et al., 2020) mention, inaccurate simulations could result in inadequate conclusions, leading to 
inappropriate and dangerous actions for the building's heritage conservation. Thus, in collaboration with the survey observations, this performance gap can also be narrowed down for better predictions. For conducting simulations of historical buildings, it is first necessary to collect as much preliminary data as possible for over a year. To understand and inculcate the usage of any material in a historical building the methodologies used in this work are important.

\section{References}

Akkurt, G. G. et al. (2020) 'Dynamic thermal and hygrometric simulation of historical buildings: Critical factors and possible solutions', Renewable and Sustainable Energy Reviews. Elsevier Ltd, 118(October 2019), p. 109509. DOI: 10.1016/j.rser.2019.109509.

Bastien, D. and Winther-Gaasvig, M. (2018) 'Influence of driving rain and vapor diffusion on the hygrothermal performance of a hygroscopic and permeable building envelope', Energy. Elsevier B.V., 164, pp. 288-297. DOI: 10.1016/j.energy.2018.07.195.

Busser, T. et al. (2018) 'Comparison of model numerical predictions of heat and moisture transfer in porous media with experimental observations at material and wall scales : An analysis of recent trends', Drying Technology. Taylor \& Francis, o(o), pp. 1-33. DOI: 10.1080/07373937.2018.1502195.

Čáchová, M. et al. (2016) 'Hygric Properties of Lime-cement Plasters with the Addition of a Pozzolana', Procedia Engineering, 151, pp. 127-132. DOI: 10.1016/j.proeng.2016.07.403.

Damle, R. and Rawal, R. (2018) 'Hygrothermal Performance of a Building across Different Climates of India Faculty of Technology, CEPT University, India Centre for Advanced Research in Building Science and Energy, CEPT University, India Abstract HAMT model verification', (2015).

Doctor-pingel, M., Vardhan, V. and et al. (2019) Use of Lime Mortar and Post-Occupancy Thermal Performance Analysis of Buildings, Encyclopedia of Renewable and Sustainable Materials. Elsevier Inc. DOI: 10.1016/B978-0-12803581-8.11308-6.

Elert, K. et al. (2002) 'Lime mortars for the conservation of historic buildings', Studies in Conservation. Int. Inst. for Conservation of Historic and Artistic Works, 47(1), pp. 62-75. DOI: 10.1179/sic.2002.47.1.62.

Energy Plus (2019) 'EnergyPlus 9.2'. Available at: https://bigladdersoftware.com/epx/docs/9-2/engineeringreference/index.html (Accessed: 12 April 2020).

EnergyPlus v9.1.o (2010) 'Input Output Reference', The Encyclopedic Reference to EnergyPlus Input and Output, pp. 1996-2016.

Gaur, R. C., and Bansal, N. K. (2002) 'Effect of moisture transfer across building components on room temperature', Building and Environment, 37(1), pp. 11-17. DOI: 10.1016/So360-1323(00)00094-9.

Govaerts, Y. et al. (2018) 'Performance of a lime-based insulating render for heritage buildings', Construction and Building Materials. Elsevier Ltd, 159, pp. 376-389. DOI: 10.1016/j.conbuildmat.2017.10.115.

Hall, C., Hoff, W. D. and Nixon, M. R. (1984) 'Water movement in porous building materials-VI. Evaporation and drying in brick and block materials', Building and Environment, 19(1), pp. 13-20. DOI: 10.1016/0360-1323(84)90009-X.

Homes, R., Roger, B. Y. and June, H. (2020) 'Expert guide to plaster in old homes', pp. 1-11.

Ingham, J. P., and Ingham, J. P. (2016) 'Diagnosing Defects in Lime-Based Construction Materials Diagnosing Defects in Lime-Based Construction Materials', 6207(June). DOI: 10.1080/13556207.2009.10785055.

Judkoff, R. D. and Neymark, J. (1998) 'The BESTEST Method for Evaluating and Diagnosing Building Energy Software', ACEE Summer Study of Energy Efficiency in Building, pp. 175-192. Available at: https://aceee.org/files/proceedings/1998/data/papers/o515.PDF\%oAhttps://www.aceee.org/files/proceedings/1998/d ata/papers/0515.PDF.

Karaglozls, A. et al. (1995) 'The effect of waterproof coating on hygrothermal performance of a high-rise wall structure', Thermal performance of the exterior envelopes of buildings, (1993), pp. 391-398.

Kielsgaard, K. (1986) 'Sorption isotherms A catalog'.

Labat, M. and Woloszyn, M. (2015) 'Moisture balance assessment at room-scale for four cases based on numerical simulations of heat - air - moisture transfers for a realistic occupancy scenario', 1493(November). DOI: 10.1080/19401493.2015.1107136.

Liu, J. Y. and Shun, C. (1991) 'Solutions of Luikov equations of heat and mass transfer in capillary-porous bodies', International Journal of Heat and Mass Transfer, 34(7), pp. 1747-1754. DOI: 10.1016/0017-9310(91)90150-D.

Lstiburek., J. (2009) Moisture Control for New Residential Buildings | BSC, ASHRAE J. Available at https://www.buildingscience.com/documents/digests/bsd-012-moisture-control-for-new-residential-buildings

(Accessed: 19 February 2020).

De Luca, R. et al. (2016) 'Spectroscopic, microchemical and petrographic analyses of plasters from ancient buildings in Lamezia Terme (Calabria, Southern Italy)', Spectrochimica Acta - Part A: Molecular and Biomolecular Spectroscopy. Elsevier B.V., 153, pp. 184-193. DOI: 10.1016/j.saa.2015.08.018.

Lucas, F. et al. (2002) 'Study of moisture in buildings for hot humid climates', Energy and Buildings, 34(4), pp. 345355. DOI: 10.1016/So378-7788(01)00115-3.

Mendes, N. et al. (2003) 'Moisture effects on conduction loads', Energy and Buildings, 35(7), pp. 631-644. DOI: 10.1016/So378-7788(02)00171-8.

Padfield, T. (1998) The role of absorbent materials in moderating changes of relative humidity.

Ravi, R. and Thirumalini, S. et al. (2018) 'Analysis of ancient lime plasters - Reason behind longevity of the Monument Charminar, India a study', Journal of Building Engineering. Elsevier Ltd, 20, pp. 30-41. DOI: 10.1016/j.jobe.2018.04.010.

Sabri, A. A. M., and Suleiman, M. Z. (2014) 'Study of the Use of Lime Plaster on Heritage Buildings' in Malaysia : A Case Study in George Town, Penang', 5, pp. 1-6. 
Snow, J., and Torney, C. (2014) 'Short guide: Lime Mortars in Traditional Buildings', Short guide, (6), pp. $16-18$. Available at: http://conservation.historic-scotland.gov.uk/hs-short-guide-6.pdf.

Taylor, S. T. et al. (1999) 'Ventilation for Acceptable Indoor Air Quality', 1999.

Toniolo, L. et al. (2011) 'Mechanical behavior of lime-based mortars after surface consolidation', Construction and Building Materials. Elsevier Ltd, 25(4), pp. 1553-1559. DOI: 10.1016/j.conbuildmat.2010.08.010.

Tran Le, A. D., Maalouf, C. and et al. (2010) 'Transient hygrothermal behavior of a hemp concrete building envelope', Energy and Buildings. Elsevier B.V., 42(10), pp. 1797-1806. DOI: 10.1016/j.enbuild.2010.05.016.

Woods, J., Winkler, J. and Christensen, D. (2013) 'Evaluation of the Effective Moisture Penetration Depth Model for Estimating Moisture Buffering in Buildings', Contract, 303(January), pp. 275-3000.

Zemanová, L., Pokorný, J. and et al. (2017) 'Properties of modified lime-based plasters for renewal of historical buildings exposed to accelerated carbonation test', Materials Science Forum, 909 MSF, pp. 286-290. DOI: 10.4028/www.scientific.net/MSF.909.286.

Zhang, M. et al. (2017) 'Moisture buffering phenomenon and its impact on building energy consumption', Applied Thermal Engineering, 124, pp. 337-345. DOI: 10.1016/j.applthermaleng.2017.05.173. 